L. Walling

N. Spayd

\title{
Impedance Measurements of RF Joint (Bellows Shield) for Collider
}

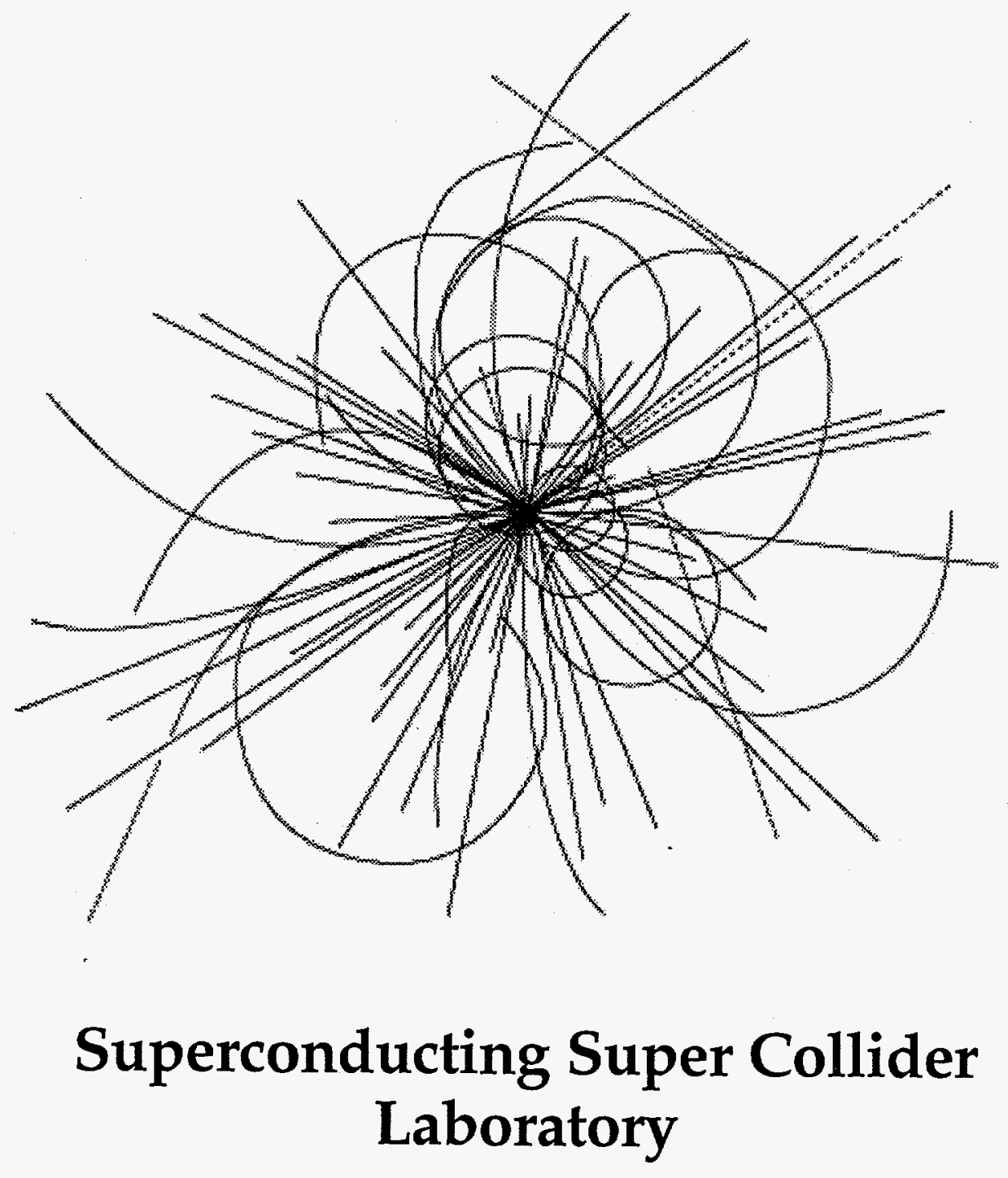

APPROVED FOR RELEASE OR

PUBLICATION - O.R. PATENT GROUP BY... S.......DATE. $\$ .3 .6 .5$. 


\section{Disclaimer Notice}

This report was prepared as an account of work sponsored by an agency of the United States Government. Neither the United States Government or any agency thereot, nor any of their employees, makes any warranty, express or implied, or assumes any legal liability or responsibility for the accuracy, completeness, or usefuiness of any information, apparatus, product, or process disclosed, or represents that its use would not infringe privately owned rights. Feference herein to any specific commercial product, process, or service by trade name, trademark, manufacturer, or otherwise, does not necessarily constitute or imply its endorsement, recommendation, or favoring by the United States Government or any agency thereof. The views and opinions of authors expressed herein do not necessarily state or reflect those of the United States Government or any agency thereot.

Superconducting Super Collider Laboratory is an equal opportunity employer. 


\section{DISCLAIMER}

Portions of this document may be illegible in electronic image products. Images are produced from the best available original document. 


\title{
Impedance Measurements of RF Joint (Bellows Shield) for Collider
}

\author{
L. Walling and N. Spayd \\ Superconducting Super Collider Laboratory* \\ 2550 Beckleymeade Ave. \\ Dallas, TX 75237 USA
}

April 1994

* Operated by the Universities Research Association, Inc., for the U.S. Department of Energy under Contract No. DE-AC35-89ER40486. 


\subsection{INTRODUCTION}

The collider ring for the Superconducting Super Collider (SSC) requires 6000 bellows to connect magnets and allow movement due to contraction of the magnets during cooling. Bellows have unacceptably high impedances in the collider ring and must be shielded. The original impedance budget (which was based on an older design) for $6000 \mathrm{rf}$ joints was estimated at $Z / n=0.12 \mathrm{ohm}$ for the longitudinal and $Z t=10 \mathrm{Mohm} / \mathrm{m}$ for the transverse impedance. With the new design it was hoped to lower these numbers to $Z / n=0.075 \mathrm{ohm}$ and $Z t=2.8 \mathrm{Mohm} / \mathrm{m}$.

\subsection{DESCRIPTION OF RF JOINT}

At the SSC we adopted a design based on rf joints used at CERN. Figure 1 shows the rf joint designed at SSC. The solid pipe side tapers to a larger diameter at the joint end. The other side, which is terminated in long narrow beryllium-copper strips, slides over the tapered end. The taper ensures that the rf contact is at the end of the solid pipe. A spring fits around the strips away from the contact plane, ensuring good pressure at the if joint.

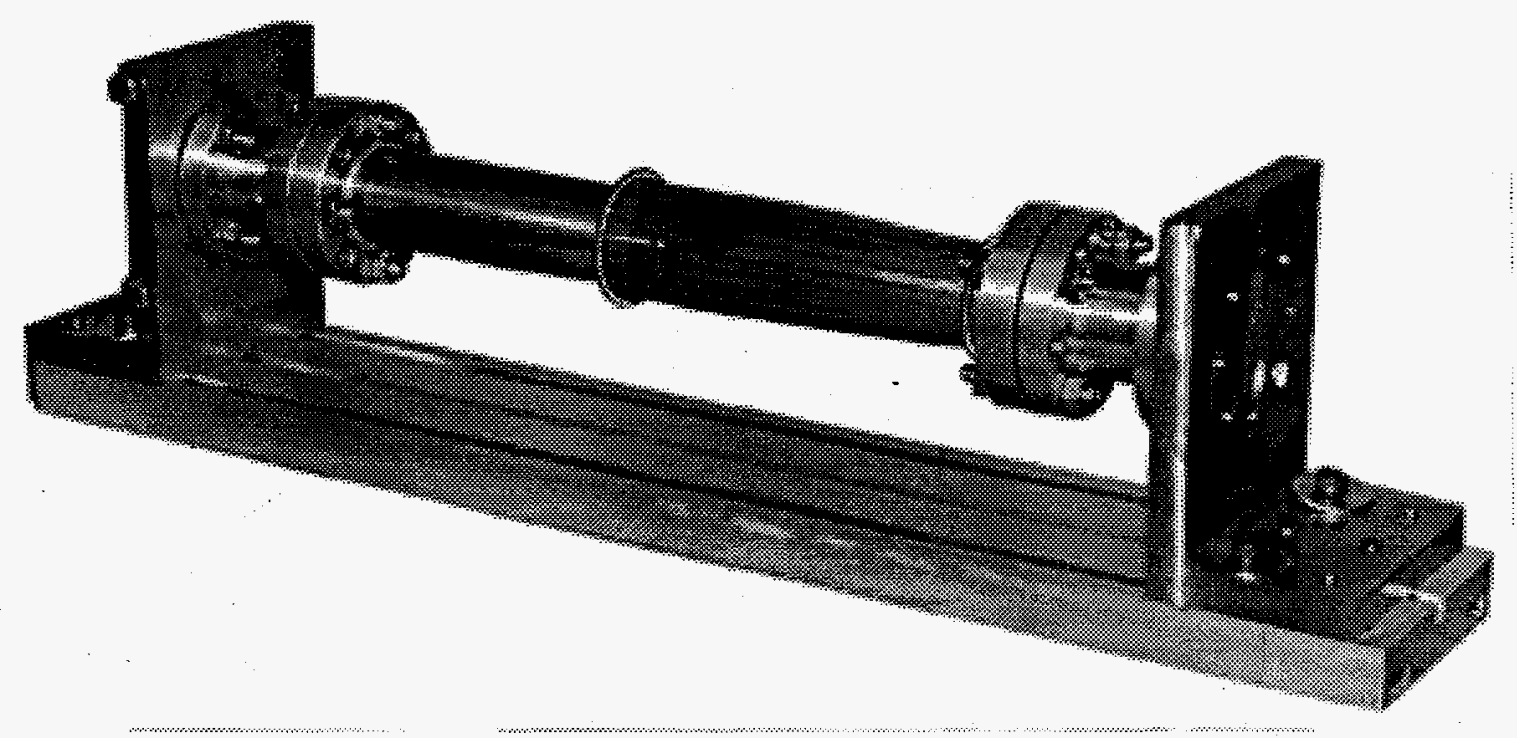

Figure 1. Photograph of $\mathrm{rf}$ Joint Mounted in Measurement Assembly.

\subsection{MEASUREMENT PROCEDURES}

Figure 2 shows the budgeted impedance per joint and the measurement threshold for both the longitudinal and transverse impedance measurements. The measurement threshold numbers indicate that the measured transmission (s21) is accurate within $1 \%$ for measuring small impedances which is indicates the measurement sensitivity. The actual measurement errors are actually closer to about $20 \%$ for impedances several times higher than the threshold level and may be closer to $50 \%$ near the threshold or at very low frequency for the transverse measurement.

The wire measurement method ${ }^{1-3}$ was used. Because the if joint is not a well-defined length a sliding measurement fixture was designed that could lock down over a range of lengths. The measurement procedure is as follows. A reference pipe of fixed length representing the length of 
the joint warm (or another pipe representing the cold length) was measured and its s-parameters stored. Then the joint was installed in the fixture which was locked to the length of the reference pipe, and its s-parameters were measured. Then s 21 of the joint was divided by $s 21$ of the reference pipe, yielding the impedance information.

Longitudinal and transverse measurements were performed for both the cold and warm lengths, and for the center conductor centered and offset. The total offset for the final measurements was $2.7 \mathrm{~mm}$.
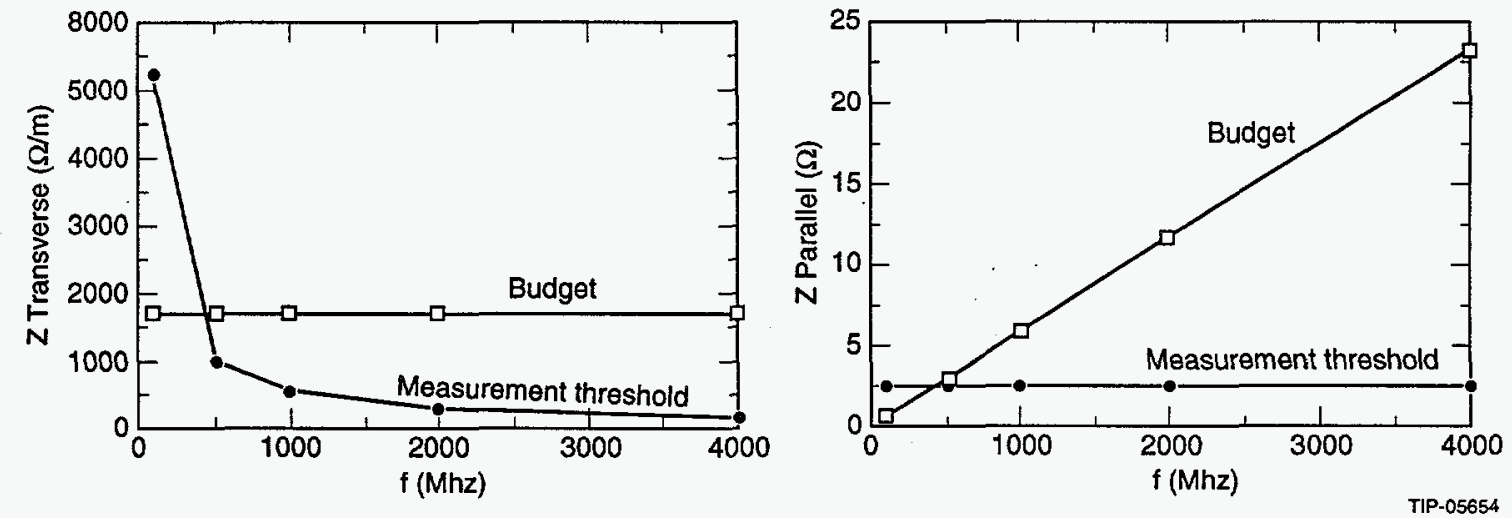

Figure 2. Measurement Thresholds and Impedance Budget (Original) for $\mathrm{rf}$ Joint.

\subsection{MEASUREMENT RESULTS}

Figure 3 shows the measured longitudinal impedances of the joint at its short range of length which represents the operating (cold) condition. For both the centered and offset cases the reactive impedance represents a $Z / n$ of about $0.03 \Omega$ The resistance results indicates only the noise level (or measurement threshold) of the measurement. For the offset case, however, there is in addition a narrow resonance at about $1300 \mathrm{MHz}$ with an impedance of about 2 ohms. This peak would most likely not change greatly with temperature since the strips are made from an alloy and alloys do not change resistivity significantly with temperature. This resonance would be due to the strips, and would probably occur at slightly difference frequencies for each rf joint, since there would be mechanical differences for each magnet interconnect. Figure 4 represents the longitudinal impedances for the warm length, which is not really pertinent for operation, but is interesting to show the changes in impedance as the rf joint expands and contracts. 
(a)

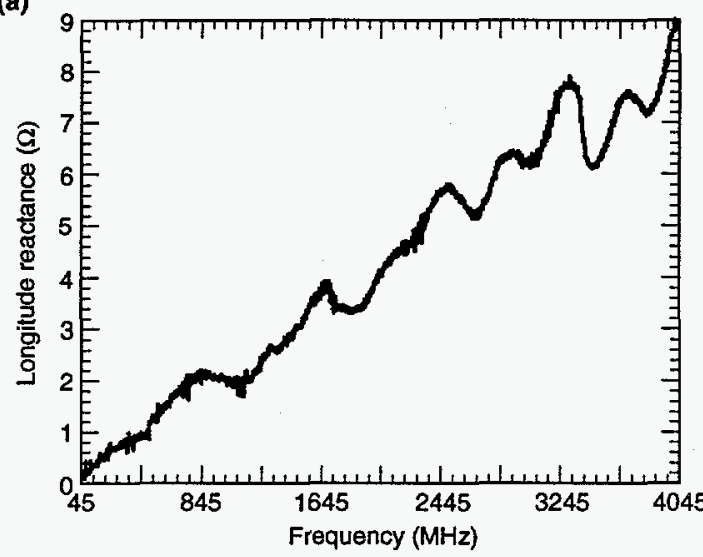

(c)

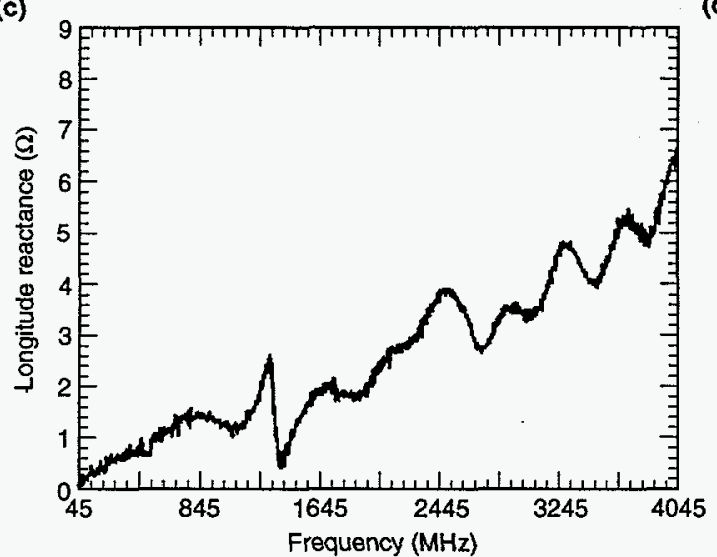

(b)

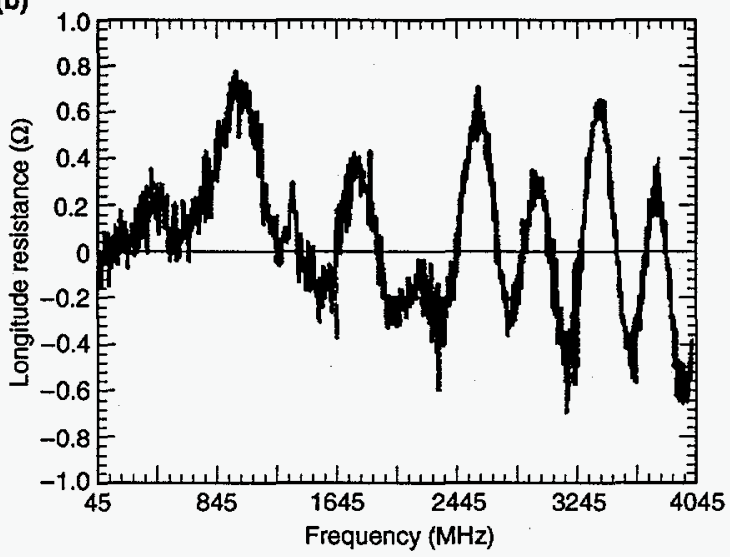

(d)

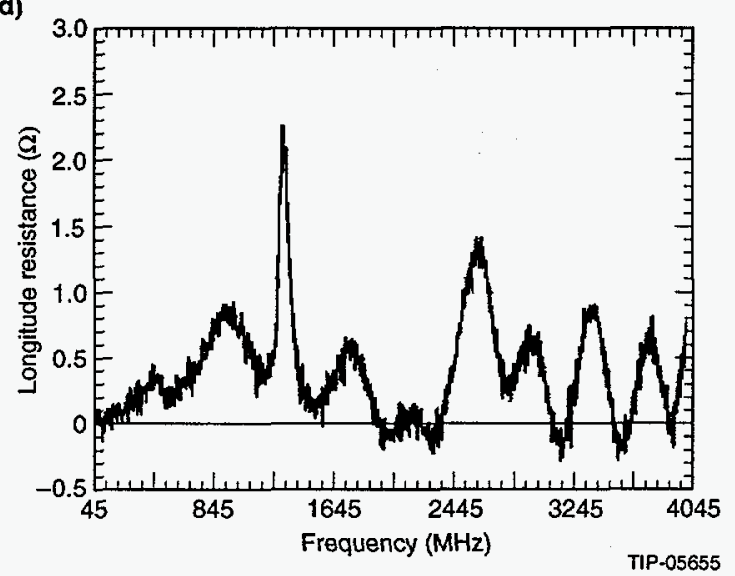

Figure 3. Longitudinal Measurement Results for Cold Length of Joint. The data in (a) and (b) represent the real and imaginary parts of the impedance for the centered beam, and the data in (c) and (d) are for the offset pipes, with all of the offset produced at one side of the joint relative to the beam.

Figures 5, 6, 7 and 8 show the measured transverse impedance. Figures 5, 6 (cold and warm lengths, respectively) are the initial measurements, which had a $20-\mathrm{mm}$ spacing between center conductors and had the entire $2.7-\mathrm{mm}$ offset on one side of the fixture, rather than equally distributed on both sides. Because the results looked rather strange, with what looked like a very broad resonance at the low frequency end, several variations on the measurements for the cold lengths were performed. First we decided to make new end fixtures which distributed the offset equally between the two ends (Figure 7); then to check the results, the measurement was repeated with the wire spacing reduced to $10 \mathrm{~mm}$ (Figure 8). 
(a)

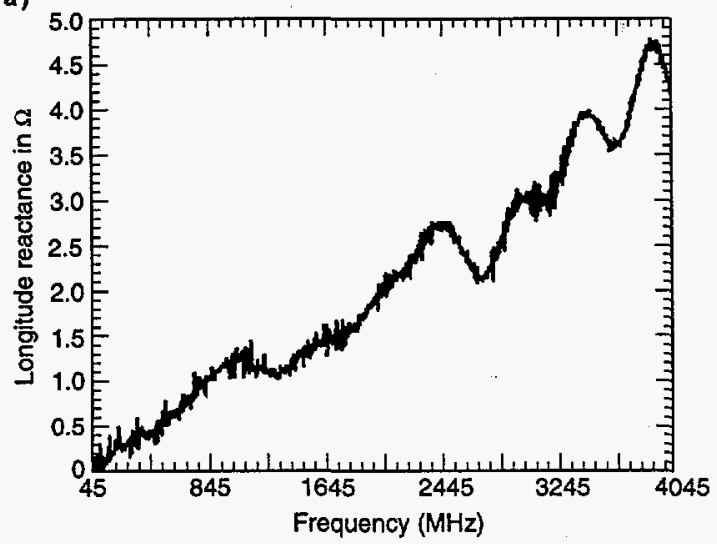

(c)

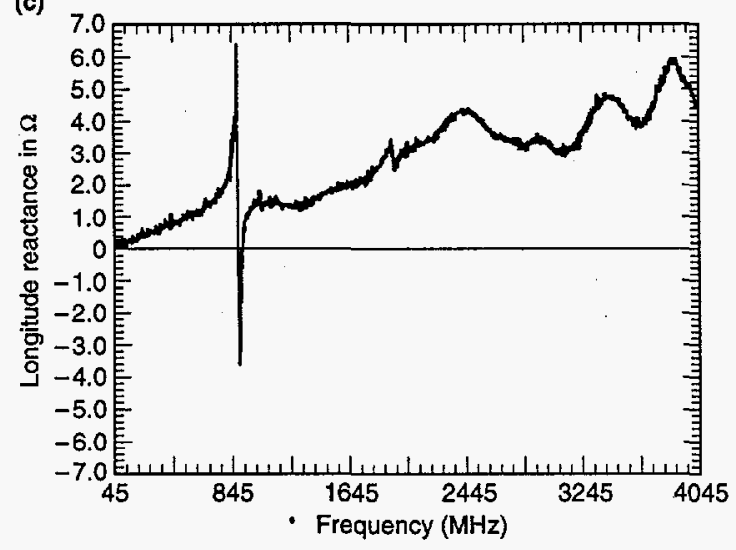

(b)

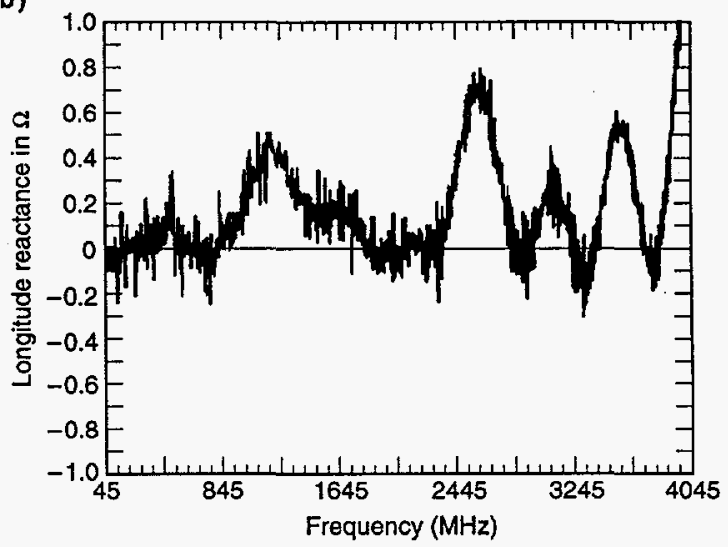

(d)

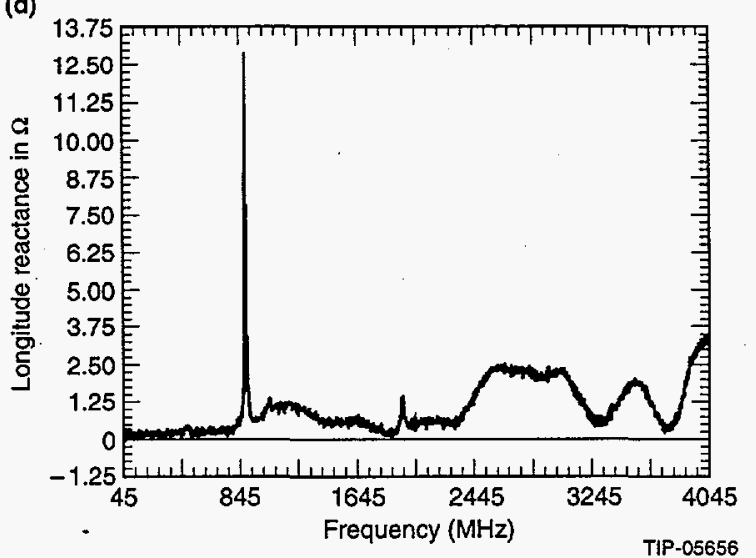

Figure 4. Longitudinal Measurement Results for Warm Length of Joint. The data in (a) and (b) represent the real and imaginary parts of the impedance for the centered beam, and the data in (c) and (d) are for the offset pipes, with all of the offset produced at one side of the joint relative to the beam.

In Figure 5, as in the longitudinal measurements, the resonances showed rather large peaks in the offset position. Also there was the curious broad-band structure at low frequency which seemed to vary noticeably with different assemblies ( $\mathrm{e}$ and $\mathrm{f}$ show the same measurements as $\mathrm{c}$ and $\mathrm{d}$ but on a subsequent day with a reassembly). We decided to refine the measurement by splitting the offset between the two ends (Figure 7). This lowered some of the resonant peaks in the 1300 $1500 \mathrm{MHz}$ region. Yet we still had the odd low-frequency behavior and decided to check once more by reducing the wire spacing to $10 \mathrm{~mm}$. The original spacing, $20 \mathrm{~mm}$, which is approximately half the pipe diameter, was chosen to maximize the sensitivity of the measurement since we were looking for impedance values near the measurement threshold. Although having a large wire spacing increases the signal, it can have the effect of increasing errors in the measurement since one then couples to higher modes of the pipe. Figure 8 shows the results with the 10-mm spacing (offset is still split between the two ends). The impedance of the mode near $1400 \mathrm{MHz}$ is thus reduced to about $2000-2500 \Omega / \mathrm{m}$, which means that the apparent impedance had been increased by having the wire spacing too large. There remains an apparent large, variable broadband lowfrequency impedance which appears to be real but needs to be investigated further, perhaps with simulations and beadpull measurements since the measurement measurement accuracy decreases drastically below $500 \mathrm{MHz}$ for the two-wire measurement (see Figure 1). 
We observed that the current design, when assembled at the warm (short) length, failed to have the fingers make contact all around the joint when offset by $2.7 \mathrm{~mm}$. However, when lengthened to the cold position, good contact was achieved.
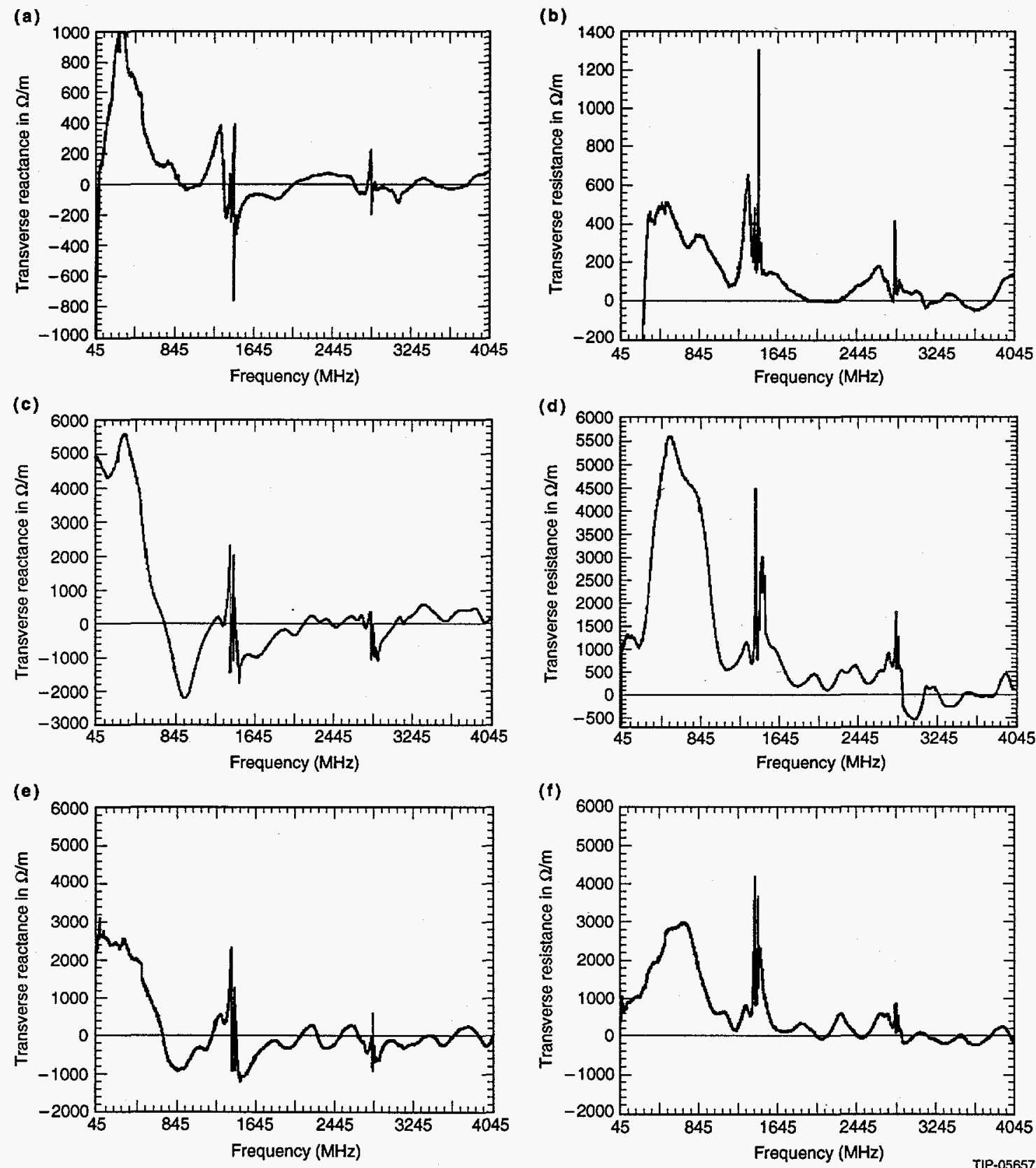

Figure 5. Transverse Measurement Results for Cold Length of Joint (wire spacing $20 \mathrm{~mm}$ ). The data in (a) and (b) represent the real and imaginary parts of the impedance for the centered beam, and the data in (c) and (d) are for the offset pipes, with all of the offset produced at one side of the joint relative to the beam. The data in (e) and (f) are repeated (hardware reassembled) measurements of the same configuration as for (c) and (d). 
(a)

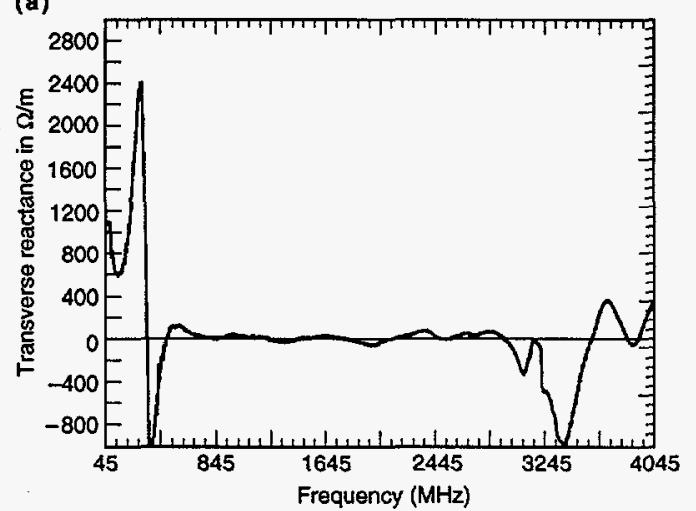

(c)

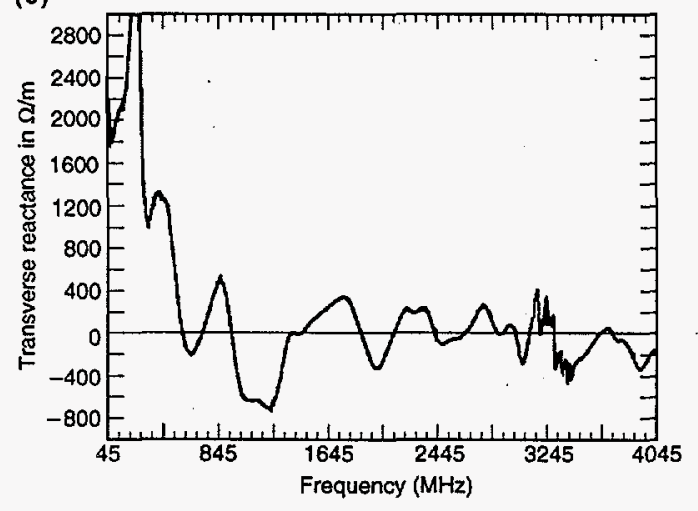

(b)

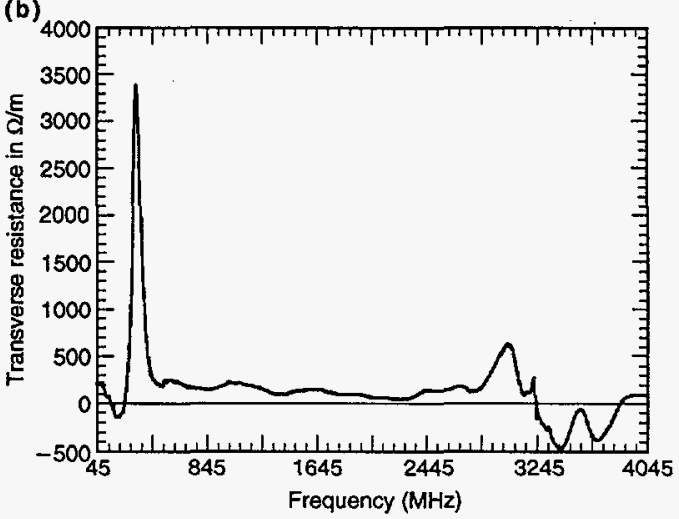

(d)

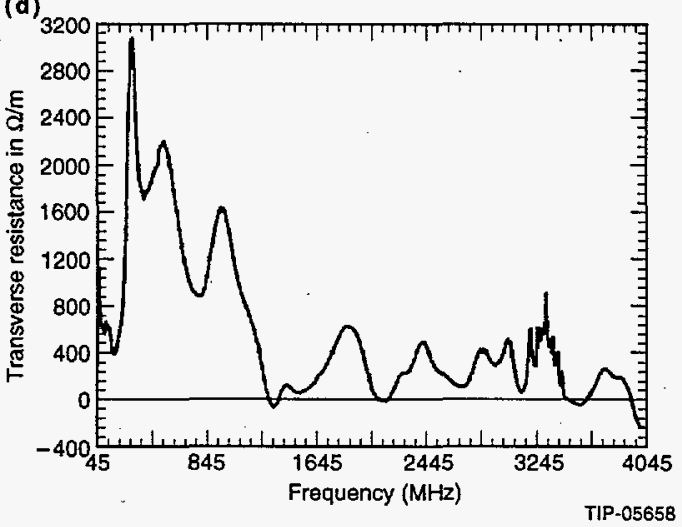

Figure 6. Transverse Measurement Results for Warm Length of Joint (wire spacing $20 \mathrm{~mm}$ ). The data in (a) and (b) represent the real and imaginary parts of the impedance for the centered beam, and the data in (c) and (d) are for the offset pipe, with all of the offset produced at one side of the joint relative to the beam.
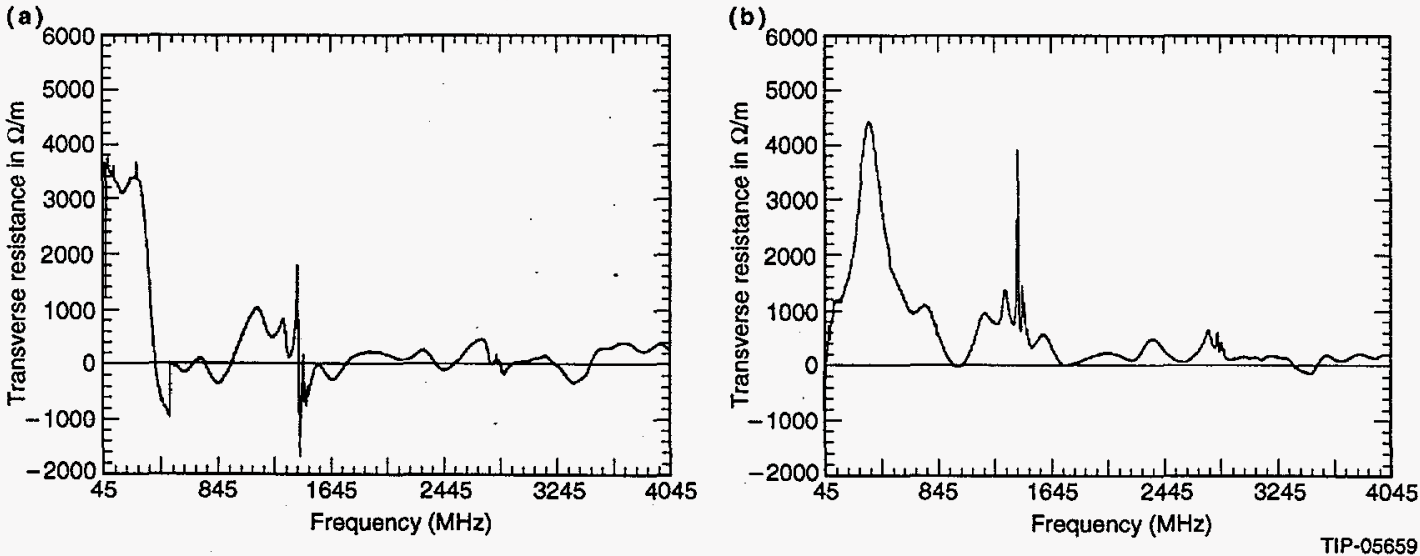

Figure 7. Transverse Measurement Results for Cold Length of Joint with Offset (wire spacing $20 \mathrm{~mm}$ ). The hardware has been changed to split the offset so that both sides have half the total offset $(1.35 \mathrm{~mm})$ relative to the beam. 
(a)

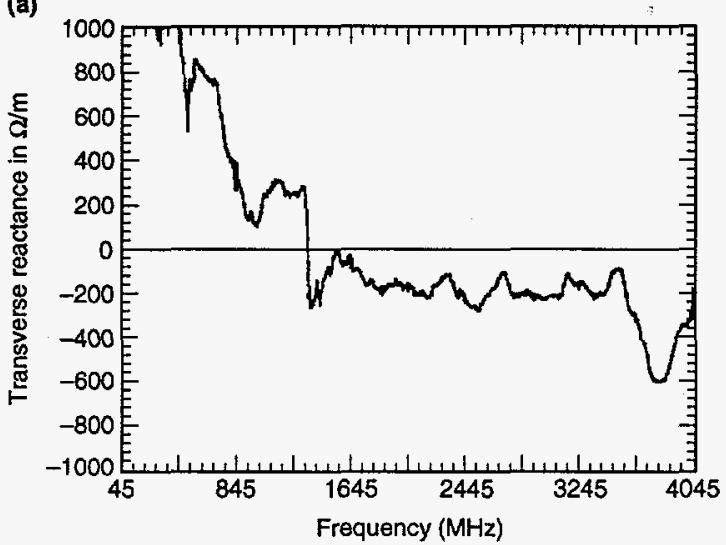

(c)

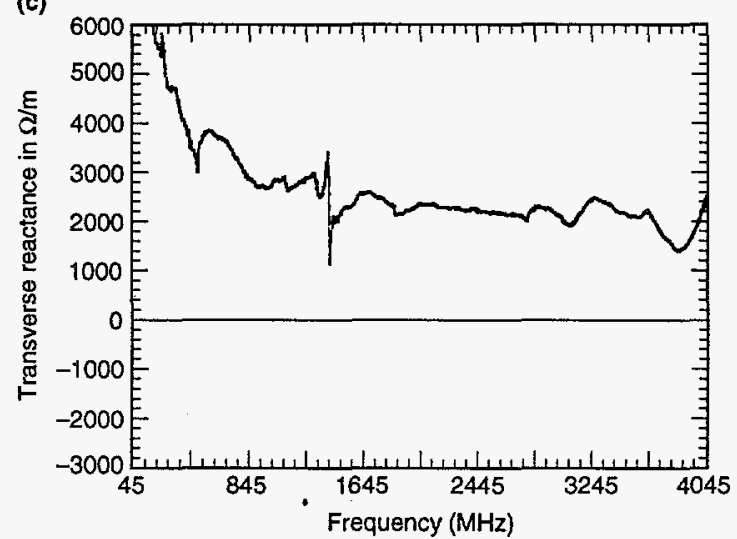

(e)

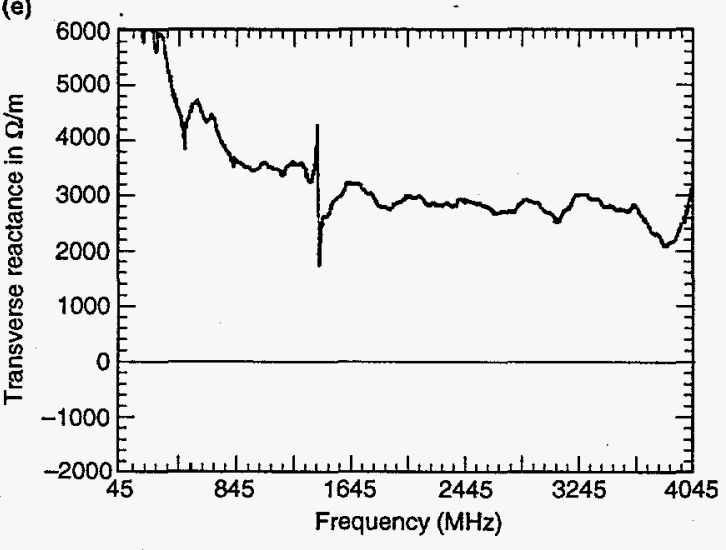

(b)

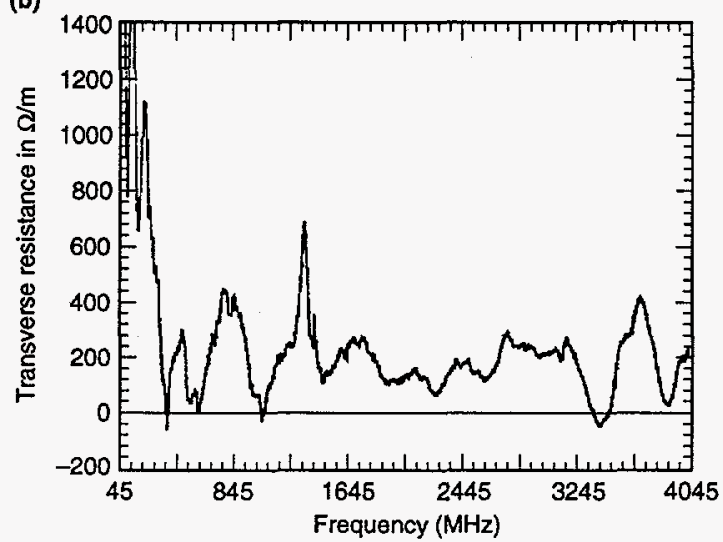

(d)

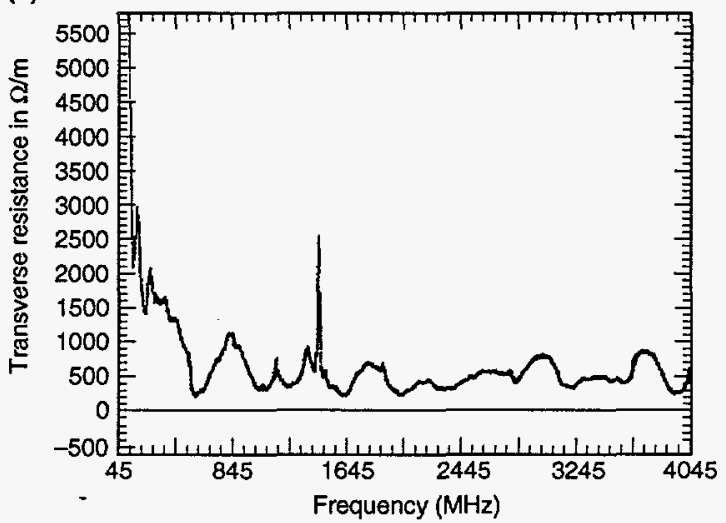

(t)

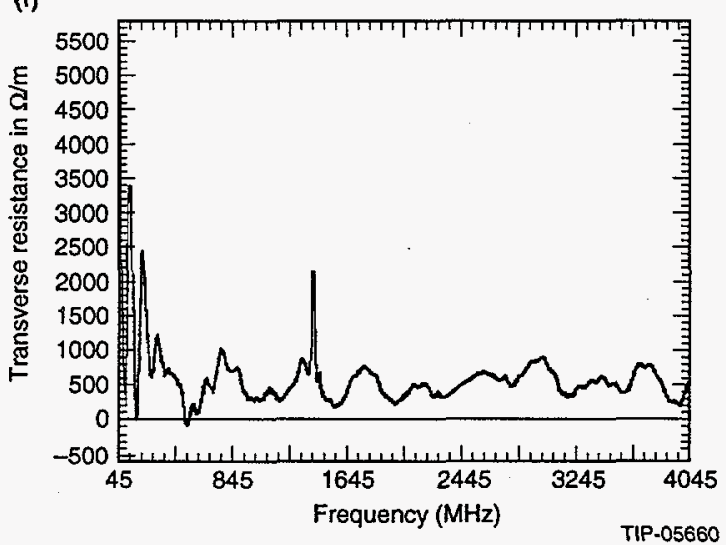

Figure 8. Transverse Measurement Results for Cold Length of Joint (wire spacing $10 \mathrm{~mm}$ ). The data in (a) and (b) represent the real and imaginary parts of the impedance for the centered beam, and the data in (c) and (d) are for the offset pipes, with the offset split between the two sides. The data in (e) and (f) are repeated (hardware reassembled) 


\subsection{CONCLUSIONS}

For the longitudinal impedance, the measurements indicate a very good design with impedances below the optimistic budget. I believe this design may need further investigation for the lowfrequency transverse impedance in the offset condition since the measurements consistently indicate an impedance 2-3 times higher than the budget for the offset condition, and within budget for the centered wire. The effect of this impedance (if it is real) is probably reduced by the fact that only a few of the joints would be offset to this maximum allowed specification, with most joints closer to being centered on the beamline. 


\section{REFERENCES}

1. L. S. Walling, D. E. McMurry, D. V. Neuffer, and H. A. Thiessen, "Transmission-Line Impedance Measurements for an Advanced Hadron Facility," Nucl. Instr. and Meth. A281 (1989) 433.

2. L. Walling, P. Allison, M. Burns, D. J. Lisks, D. E. McMurry and A. H. Shapiro, "Transverse Impedance Measurements of Prototype Cavities for a Dual-Axis Radiographic Hydrotest (DARHT) Facility," 1991 IEEE PAC, San Francisco, Ca. May 1991.

3. "Transverse Coupling Impedance Measurement Studies of Low-Q Cavities," 1990 Linear Accelerator Conference, Albuquerque, NM, September 1990. 